\title{
Licenciandos em Computação: experiências formativas proporcionadas pelo PIBID e a busca pelo reconhecimento profissional
}

\author{
Cristina Carvalho de Almeida* \\ Noemi Marcia Alvarenga Mateus**
}

\begin{abstract}
Resumo
Neste texto pretende-se apresentar experiências formativas adquiridas com a participação dos Licenciandos em Computação do Instituto Federal de Educação, Ciência e Tecnologia do Sul de Minas Gerais (IFSULDEMINAS) no Programa Institucional de Bolsas de Iniciação à Docência (PIBID) e refletir sobre o uso das Tecnologias Digitais de Informação e Comunicação (TDIC) nas escolas da região próxima à Machado/MG enquanto os licenciandos buscam o reconhecimento profissional docente. A pesquisa, de abordagem qualitativa, foi realizada através de análise documental, participação em rede social de apoio à valorização da carreira docente assim como através da aplicação de questionários estruturados para Licenciandos em Computação e diretores das escolas da região. A participação em projetos de extensão, como o PIBID, foi considerada pelos licenciandos uma forma de valorização do curso de Licenciatura em Computação e, através das ações desenvolvidas, a comunidade escolar e a sociedade são beneficiadas, ao mesmo tempo em que reconhecem as habilidades e competências deste profissional.
\end{abstract}

Palavras-chave: Licenciatura em Computação; Tecnologias na educação; Experiências de formação docente.

\section{Licensing in computing: formative experiences provided by PIBID and the quest for professional recognition}

\begin{abstract}
\section{Introdução}

As tecnologias fazem parte do cotidiano das pessoas, que cada vez mais têm necessidades de interação e conexão. Ler e digitar mensagens, manipular instruções eletrônicas, acessar redes sociais e realizar serviços diversos pelo ciberespaço, ambiente de comunicação proporcionado pela interconexão mundial de computadores, viraram um hábito entre as pessoas com $o$ advento das Tecnologias Digitais de Informação e Comunicação (TDIC).

Com o cenário educacional não poderia ser diferente. Nos últimos anos têm se falado muito no uso do computador como mediador do processo de ensino e aprendizagem e como essa ferramenta pode proporcionar mudanças qualitativas na educação.

No momento em que as Tecnologias de Informação e Comunicação revolucionam o mundo e invadem as escolas, a educação

* Endereço eletrônico: criscalmeida@gmail.com

** Endereço eletrônico: noaalvarenga @ gmail.com
\end{abstract}

This article intends to provide formative experiences with the participation of licensing in Instituto Federal de Educação, Ciência e Tecnologia do Sul de Minas Gerais (IFSULDEMINAS) in the Scholarship Program Initiation to Teaching (PIBID) and reflect on the use of technologies digital Information and Communication (TDIC) in schools next to Machado/MG region while undergraduates seeking professional recognition teaching. The research, a qualitative approach, was performed through document analysis, participation in social support network and enhancement of teacher through the application of structured questionnaires for licensing students in Computer and directors of schools of the region. Participation in outreach projects, such as PIBID, was considered by undergraduates a form of appreciation Degree in Computing and actions developed through the school community and society are benefited while recognizing the skills and competencies of professional.

Keywords: Licenciate in Computing; Technologies in education; Experiences of teacher training.

pede uma nova proposta de trabalho. As Tecnologias de Informação e Comunicação afetam a maneira de compreender o mundo, as formas de viver, de conviver e os modos de fazer e de ser. (DALABONA, 2005, p. 207).

Por meio de iniciativas governamentais, as escolas públicas receberam equipamentos tecnológicos, mas percebe-se não ter havido um planejamento estratégico sobre as possibilidades de uso destes recursos nas atividades de ensino e aprendizagem. A força do movimento de implantação da tecnologia na educação foi definitivamente notada na década de 90 . Entretanto, o computador nas escolas estava diretamente relacionado à automatização de processos administrativos e burocráticos. Diante desta perspectiva, o computador era pouco usado em sala de aula e, de forma geral, era visto como um recurso útil para a elaboração de provas, planejamento e 
pesquisas na internet (BORBA, 2000).

Segundo Perrenoud (2000), a escola não pode ignorar o que se passa no mundo. É essencial que as escolas e os professores estejam inseridos no contexto da informática para fins pedagógicos, mas muitas vezes deixam de usufruir das tecnologias em suas aulas, pois não estão preparados para a era do ensino digital. Interessante destacar que o não uso da tecnologia não é predominante em todas as atividades do professor:

A maioria dos professores sabe utilizar as TIC para uso pessoal, mas tem dificuldades e não aceita o uso das mesmas em sua prática pedagógica. A pesquisa identificou que o problema da utilização das TIC em sala de aula pode estar relacionado à formação desses professores e como eles percebem as potencialidades dessa ferramenta (BITTENCOURT IBSEN; BITTENCOURT IVANICE, 2010).

Mais intrigante ainda se mostra o fato de muitos alunos chegarem à educação básica sabendo utilizar recursos tecnológicos, mas que, na maioria das vezes, interessam-lhes apenas pelo lazer proporcionado por jogos, mensagens virtuais e redes sociais. Seria este fato um agravante ou um intensificador para a identificação das potencialidades da tecnologia na educação?

Mesmo diante da popularização da tecnologia, o fato de a escola possuir ou não um profissional capaz de utilizá-la agregando-a as aulas de outras ciências já existentes não parece ser solução eficaz para sua efetiva utilização na educação. Torna-se evidente a necessidade de refletir sobre as possíveis formas de interação dos recursos tecnológicos com os processos didáticopedagógicos.

As escolas, quando preparadas para as transformações tecnológicas que vêm acontecendo no âmbito educacional, não privam seus alunos dessas inovações, e, segundo Kenski (1997, p.36), "as velozes transformações tecnológicas da atualidade impõem novos ritmos e dimensões à tarefa de ensinar e aprender. É preciso que se esteja em permanente estado de aprendizagem e de adaptação ao novo".

Quando inseridas neste contexto, as escolas prepararam os alunos para a sociedade contemporânea e globalizada, na qual os artefatos tecnológicos ganham destaques a cada dia e o conhecimento torna-se o eixo primordial para o desenvolvimento que permite melhorar a qualidade de vida dos alunos enquanto cidadãos críticos e reflexivos. Acreditamos que as TDIC não são a solução para os problemas da escola, mas podem, através de dinâmicos processos de interação e comunicação, colaborar para o enriquecimento das práticas educativas e consequentemente contribuir para a construção do conhecimento e a valorização do processo pedagógico.

Foi com esses pressupostos que o IFSULDEMINAS implantou em 2009 o curso de Licenciatura em Computação, visando formar professores para atuar em diferentes níveis de ensino bem como permitir o reconhecimento profissional de seus egressos, considerando-se que esses profissionais podem ser o elo de integração entre as disciplinas curriculares obrigatórias e os recursos computacionais, favorecendo o ensino multidisciplinar.

Através de uma pesquisa de abordagem qualitativa, foram utilizados como instrumentos de produção de dados a pesquisa documental, a participação em redes sociais de apoio à profissão docente e questionários estruturados para os alunos do curso de Licenciatura em Computação do Instituto Federal de Educação, Ciência e Tecnologia do Sul de Minas Gerais (IFSULDEMINAS), destacando-se que alguns deles participam do Programa Institucional de Bolsas de Iniciação à Docência (PIBID). Para subsidiar as análises referentes ao uso das TDIC no ambiente pedagógico da educação pública, bem como para identificar o real contexto no qual poderão atuar os Licenciados em Computação, optou-se também pela aplicação de questionários para os diretores de escolas de nível básico da região, sendo estes em menor número que o quadro de professores, possibilitando abranger um número maior de escolas.

$\mathrm{O}$ presente trabalho tem por objetivo discutir o potencial pedagógico dos alunos do curso de Licenciatura em Computação, procurando, desta maneira, valorizar os egressos, dando visibilidade à profissão do professor de computação perante a comunidade acadêmica e gestores da educação básica, visando garantir vagas para esse profissional nas escolas das redes municipais e estaduais.

A necessidade da busca pela valorização dos professores Licenciados em Computação, contexto desta pesquisa, foi percebida pelas pesquisadoras enquanto planejavam e desenvolviam as atividades pedagógicas do PIBID, que, por ser um projeto de iniciação à docência, permitiu o contato com as escolas de educação básica da cidade de Machado / MG. Emergiu desta oportunidade a vivência da precária situação tecnológica das escolas públicas estaduais não apenas no sentido de montagem e manutenção de Laboratórios de Informática, mas também no sentido da utilização dos recursos disponíveis. 
Destarte, o texto está organizado nas seguintes seções: inicialmente discutimos o perfil da Licenciatura em Computação e o papel do PIBID na formação dos licenciandos; em seguida apresentamos os procedimentos metodológicos da pesquisa e os seus resultados; e, finalmente, nossas considerações finais.

\section{Licenciatura em Computação: uma necessidade atual?}

Segundo Almeida e Junior (2000), na década de 1980, com a diminuição dos preços dos computadores e a invenção das interfaces gráficas de fácil manipulação, tornou-se possível a criação de projetos de utilização da informática na educação.

No Brasil, a iniciativa de introduzir a computação na educação como instrumento de mediação no processo de ensino e aprendizagem partiu do governo brasileiro. A Secretaria Especial de Informática (SEI) implantou, em 1980, a Comissão Especial de Educação, que tinha o objetivo de estabelecer normas e diretrizes para a área de informática na educação. Experiências desse e de outros projetos do governo fizeram com que a SEED/MEC (Secretaria de Educação a Distância / Ministério da Educação) lançasse, em 1997, um de seus programas que contribuíram para a formação e capacitação contínua do professor no uso das novas tecnologias nas escolas: o Programa Nacional Tecnologia Educacional (ProInfo), desenvolvido em parceria com governos estaduais e municipais, que buscava inserir as TDIC nas escolas públicas de ensino fundamental e médio.

Segundo Almeida (2000), o ProInfo tornouse um marco na democratização do acesso as TDIC e distribuiu, em sua primeira fase, 30.253 microcomputadores a 2.276 escolas públicas, tendo como estratégia facilitar a apropriação das tecnologias e seu uso como instrumento de transformação do sistema educacional.

Entretanto, ao frequentarmos algumas escolas públicas da região de Machado/MG, percebemos que na maioria delas os equipamentos tecnológicos existem, mas frequentemente ficam armazenados em locais de difícil acesso ou, em alguns casos, estão disponíveis em Laboratórios de Informática, mas não são utilizados pelos professores. Os fatores para essa não utilização são muitos e requerem ampla discussão pois não se referem simplesmente à disponibilidade ou acesso a estes recursos. Borba (2002) aponta que

o desafio que as novas tecnologias põem para os educadores e educandos é o de encontrar problemas que sejam adequados aos novos sistemas, e não pensar no que se perdeu quando os computadores não estavam presentes e tínhamos que estudar questões que hoje estão facilmente acessiveis em bancos de dados eletrônicos (Internet, Intranet etc) BORBA (2002, p.158).

Dominicé (2010, p. 94) afirma que o professor é sempre evocado, seja por um fracasso seja por um sucesso. Entretanto, não acreditamos que a inserção das TDIC na educação possa gerar desconforto profissional para professores. Baseamonos em Borba (2002), quando elucida que é mais importante delimitar um problema do que conhecer uma técnica que resolva todos os problemas. E, perante essa reflexão, não podemos generalizar e atribuir à capacitação dos professores o uso ou não dos recursos tecnológicos para o desenvolvimento das atividades pedagógicas.

Diante deste cenário, identificou-se a necessidade de uma formação de professores licenciados na área de computação baseando-se na Lei de Diretrizes e Bases da Educação Nacional (LDB), $n^{\circ} .9394$ de 20 de dezembro de 1996. A Universidade de Brasília (UnB) foi a pioneira, implantando em 1997 o primeiro curso de Licenciatura em Computação.

O objetivo da criação do curso de Licenciatura em Computação era formar um novo perfil de profissional com grande potencial, habilidades técnicas e pedagógicas e vasto conhecimento de Ciência da Computação. Soma-se a este perfil o aprendizado de técnicas didáticopedagógicas e formação educacional para atuação nas escolas públicas, levando as TDIC até as salas de aula.

O IFSULDEMINAS - câmpus Machado foi uma das instituições a criar, em 2009, o curso de Licenciatura em Computação, que foi autorizado pela Resolução $n^{\circ} 6$ do Conselho Superior, de 24 de Novembro de $2009^{1}$. Julgamos oportuno apontar que a abertura deste curso procurou atender às exigências da Lei $\mathrm{n}^{\circ} 11.892$, de 29 de dezembro de 2008, na qual se estabeleceu que os Institutos Federais de Educação, Ciência e Tecnologia devem garantir, no mínimo, 20\% (vinte por cento) de suas vagas para cursos de licenciatura, bem como para programas especiais de formação pedagógica. Tal medida tem como objetivo a formação de professores para a educação básica, sobretudo nas áreas de ciências e matemática, e para a educação profissional. Outros dois fatores motivadores para a abertura do curso neste instituto foram a disponibilidade de corpo docente da área de 
Computação e Pedagogia bem como a ausência de curso semelhante na região de Machado. O curso de Licenciatura em Computação do Câmpus Machado é reconhecido pelo MEC, desde 2012, com nota 4.

A proposta metodológica do curso de Licenciatura em Computação do IFSULDEMINAS é:

$O$ aprofundamento do conhecimento em computação e educação, levando em consideração a pesquisa e o ensino, a partir das bibliografias mais atuais, visando desenvolver o gosto e as habilidades tanto para o ensino quanto para a busca por maior aprimoramento nas diferentes áreas da computação. Para tanto enfatiza a técnica das aulas direcionadas e estimulam a postura crítica, a participação do aluno $e$ $o$ desenvolvimento do raciocínio lógico (IFSULDEMINAS, 2012, p.14).

O curso de Licenciatura em Computação do IFSULDEMINAS tem como objetivo geral a contribuição para o desenvolvimento de habilidades e atitudes que consolidem a capacidade crítica e reflexiva, capazes de intermediar o processo de ensino e aprendizagem, dando ao licenciado a dimensão da área de computação e os desafios do ensino na área, partindo do princípio de que esse profissional deverá ter a consciência de formação permanente (IFSULDEMINAS, 2012, p.15). Cabe destacar as palavras de Demo (2011, p.32): "toda mente que sabe pensar é sempre uma intervenção ambulante".

Consta no currículo do licenciando em Computação, além das disciplinas tecnológicas, a formação pedagógica para atuar no campo da docência e de gestão de projetos escolares. Os alunos da Licenciatura em Computação são preparados para atuação nas escolas públicas, contribuindo para inovações das práticas pedagógicas.

Conforme o Projeto Pedagógico do Curso (PPC) de Licenciatura em Computação do IFSULDEMINAS e o Parecer CNE/CP 9/2001, que trata das Diretrizes Curriculares Nacionais para a Formação de Professores da Educação Básica em cursos de licenciatura, urge inserir as diversas tecnologias da informação e da comunicação no desenvolvimento dos cursos de formação de professores, preparando-os para a finalidade mais nobre da educação escolar: a gestão e a definição de referências éticas, científicas e estéticas para a troca e negociação de sentido, que acontece especialmente na interação e no trabalho escolar coletivo. Gerir e referir o sentido são ações importantes, e o professor precisa aprender a desenvolvê-las em ambientes reais e/ou virtuais.

Segundo Valente (1998), a Informática Educacional é o processo que coloca o computador e sua tecnologia a serviço da educação e pode contribuir para a formação dos alunos, auxiliandoos a ser não meros consumidores, mas elaboradores de conhecimento. Portanto, todos os aspectos e as variáveis neste processo deverão estar subordinados à consideração de que a essência é de natureza pedagógica, buscando assim melhorias do processo de ensino e aprendizagem de forma a levar o aluno a aprender e o professor a orientar e auxiliar esta aprendizagem.

Entre as habilidades desenvolvidas pelos licenciandos em Computação cita-se a criação de projetos interdisciplinares que permitam a inclusão da informática no processo de ensino e aprendizagem dos conteúdos ministrados por outras áreas do conhecimento por meio da interação com professores dos diferentes níveis e modalidades de ensino. Faz-se necessária a aquisição de conhecimentos nas áreas de computação e educação e em várias disciplinas específicas que trabalham áreas temáticas referentes à formação do profissional do licenciado (IFSULDEMINAS, 2012, p.17).

Conforme Alonso (1998), os artefatos tecnológicos e a sua cultura devem ter um lugar no desenvolvimento curricular, assim como um tratamento específico da parte do método didático. Abordar esta tarefa requer não somente um conjunto de conhecimentos que facilitem e racionalizem as decisões, mas também o confronto de um problema ideológico de enorme importância pedagógica e de organização da escola. É neste contexto que se insere o licenciando em Computação.

Os alunos da Licenciatura em Computação não apenas se formam para atuar como professores da área tecnológica, mas também podem estabelecer parcerias com os professores das escolas. $\mathrm{O}$ potencial didático e a bagagem de conhecimento tecnológico dos egressos deste curso podem auxiliar no planejamento e execução de projetos que utilizam as TDIC para o enriquecimento pedagógico das atividades docentes. Para Delory-Momberger (2008, p. 87), a partir dos anos 80, emergiram formas econômicas que estavam vinculadas tanto à mundialização da produção e do mercado quanto à revolução da informática. Neste contexto, a autora ressalta a formação que parte dos indivíduos objetivando que reconheçam suas competências e construam percursos de formação personalizados.

Cabe ressaltar a importância da formação de professores para a utilização das ferramentas tecnológicas do trabalho colaborativo e da parceria 
entre universidade e escola, conforme destaca Mendes (2013). Segundo esta autora, inúmeros são os trabalhos, livros, dissertações de mestrado e teses de doutorado que abordam as diversas dimensões políticas, sociais, pedagógicas e culturais entre a educação e as tecnologias de informação e comunicação. Entretanto, é necessário pesquisar e conhecer, no contexto educativo, o que essas tecnologias significam para o professor e como os alunos podem utilizá-las objetivando a produção de conhecimento.

\section{O PIBID e a valorização da Licenciatura em Computação}

O Programa Institucional de Bolsa de Iniciação à Docência (PIBID) foi instituído a partir da Portaria Normativa $\mathrm{n}^{\circ} 38$, de 12 de dezembro de 2007 (BRASIL, 2007), e surgiu da ação conjugada do Ministério da Educação (MEC), por intervenção da Secretaria de Educação Superior (SESu), da Coordenação de Aperfeiçoamento de Pessoal de Nível Superior (CAPES) e do Fundo Nacional de Desenvolvimento da Educação (FNDE), procurando incentivar a iniciação à docência de estudantes de nível superior, em cursos de licenciatura, para atuar na educação básica pública.

No IFSULDEMINAS, o PIBID teve início em junho de 2011. Os alunos de iniciação à docência do PIBID Computação, um dos subprojetos do câmpus Machado e contexto no qual estão inseridos alguns dos sujeitos desta pesquisa, procuram colaborar para o enriquecimento das práticas pedagógicas da disciplina de Matemática no ensino fundamental através do uso das TDIC e de materiais pedagógicos para o ensino dos conceitos elementares desta disciplina. Como a informática não é disciplina curricular obrigatória nas escolas do estado de Minas Gerais, a associação da Computação à Matemática se fez necessária no momento da elaboração do projeto e justifica-se, já que os conceitos matemáticos muito se aproximam das questões lógicas e da computação.

Os alunos de iniciação à docência do PIBID Computação se empenham em mostrar o quanto o uso da tecnologia pode ser um importante recurso para a educação. Uma das maiores dificuldades encontradas pelos pibidianos era o fato de uma escola parceira do projeto ainda não possuir, até o início de 2015, laboratório de informática e, em outras escolas que o possuem, ele não era efetivamente utilizado pelos alunos e professores.

Para Zeichner (2009), é preciso analisar o impacto sobre a qualidade do ensino e aprendizagem do aluno a partir das oportunidades que lhes são oferecidas no contexto de formação dos cursos de licenciatura. Com o PIBID, os alunos da Licenciatura em Computação estão tendo a oportunidade de vivenciar a realidade das escolas públicas e mostrar suas competências e habilidades, podendo contribuir para o enriquecimento do processo de ensino e aprendizagem de Matemática.

Os bolsistas de iniciação à docência têm o privilégio de estar em constante aprendizado, pois, segundo Almeida e Junior (2000), "o prazer do conhecimento é um impulso admirável que a evolução parece ter selecionado como forma de nos induzir à aprendizagem”.

Entre os objetivos dos alunos de iniciação à docência do PIBID Computação, cita-se a colaboração para com os professores e alunos no uso das tecnologias em sala de aula. Assim como Freire (1995, p. 98), acreditamos que o uso de computadores nas escolas "em lugar de reduzir, pode expandir a capacidade crítica de nossos meninos e meninas". A inserção, no contexto educacional, dos artefatos tecnológicos, dos programas computacionais educacionais e a produção de materiais pedagógicos podem possibilitar uma aproximação do abstrato. Para Almeida e Júnior (2000, p. 18) “com computadores, conseguimos ir onde parecia impossível, podemos manipular o que é intangível, ver o que de tão diminuto é invisível".

Conforme Almeida (2000, p.5), "a tarefa de transformar nosso complexo sistema educacional exige múltiplas ações. As mais importantes são as capazes de provocar impactos significativos na qualidade da formação e da prática do professor". Percebemos através dos relatos dos alunos de iniciação à docência, durante as reuniões do PIBID Computação, que a oportunidade que lhes é dada através deste projeto contribui para que possam experimentar a prática docente antes mesmo das atividades que lhes são obrigatórias dentro da matriz curricular da licenciatura como, por exemplo, o estágio supervisionado. A antecipação dessa experiência faz com que eles passem a planejar e desenvolver atividades pedagógicas com a orientação de professores que atuam nas escolas públicas e que pacientemente lhes mostram os percursos cotidianos dos processos de ensino e aprendizagem.

Segundo Perrenoud (2000), as estratégias que os professores podem desenvolver são: criar, intensificar e diversificar o desejo de aprender; favorecer e reforçar a decisão de aprender para que aluno encontre o prazer de aprender e o desejo de saber. Estes são os principais desejos dos bolsistas do PIBID Computação: despertar nos alunos da educação básica o prazer pelo conhecimento, utilizando as TDIC para reforçar essa tarefa tão 
relevante, que é "arte de aprender e ensinar". Além desta possibilidade, o PIBID tem se destacado dentro da comunidade acadêmica do curso de Licenciatura em Computação do IFSULDEMINAS como uma possibilidade de aprendizagem através da contínua troca de experiências entre professores de nível superior, que coordenam o projeto, professores da educação básica, que os supervisionam nas escolas estaduais e entre os próprios colegas que se encontram em formação inicial.

As ações do PIBID Computação também permitem aos alunos de iniciação à docência a publicação de vários artigos e a participação em eventos com troca de experiências e aprendizagem constante. Entre as recompensas acadêmicas da participação no projeto citam-se: docência compartilhada; enriquecimento profissional como docente; motivação dos alunos das escolas estaduais na participação das atividades. Estas características são enaltecidas por Diniz-Pereira (2014), ao afirmar que a questão central das pesquisas antes se pautava em como formar o professor e após os anos 2000 passou a focar em como se constituem os educadores.

\section{Caminhos norteadores da pesquisa}

Esta pesquisa caracteriza-se por uma abordagem qualitativa. Inicialmente foi realizado um estudo bibliográfico sobre o uso das TDIC no contexto educacional e a relevância da formação específica neste sentido. Esta etapa teve como objetivo obter informações relevantes sobre o tema, dando enfoque sobre o que pensam autores como: Alonso (1998), Valente (1998), Almeida e Junior (2000), Borba (2000 e 2002), Dalabona (2005), Bittencourt e Bittencourt (2010) entre outros, sobre a introdução das tecnologias no ambiente educacional e seu uso efetivo como ferramenta mediadora do processo de ensino e aprendizagem.

$\mathrm{Na}$ pesquisa documental foi realizada uma análise reflexiva sobre o Projeto Político Pedagógico do curso de Licenciatura em Computação do IFSULDEMINAS - Câmpus Machado, o Currículo de Referência para Cursos de Licenciatura em Computação da Sociedade Brasileira de Computação e a Lei de Diretrizes e Bases da Educação Nacional.

Também como parte dos procedimentos metodológicos cita-se a participação numa rede social intitulada "Licenciados em Computação: queremos contato", , que teve por objetivo identificar, através das postagens de seus membros, quais são as perspectivas de trabalho para os licenciados em Computação. Na descrição do grupo, disponível na rede social, consta o apelo:
"Queremos a sua ajuda para reconhecimento da nossa profissão".

Conforme André (2011), o espaço e tempo são condições necessárias para a produção da pesquisa, além de recursos materiais, humanos e financeiros. Esta pesquisa foi desenvolvida com apoio financeiro do IFSULDEMINAS - Câmpus Machado no que tange ao deslocamento de uma das pesquisadoras, licencianda à época da produção dos dados, às cidades da região para realizar as entrevistas estruturadas com os diretores das escolas públicas.

Foram elaborados e aplicados os questionários estruturados para os licenciandos em Computação. Para André (2011), os pesquisadores voltaram a utilizar os questionários, banidos nos anos 90, o que demonstra uma relativa diminuição do preconceito sobre dados quantitativos, embora este não tenha sido o enfoque analítico adotado nesta pesquisa.

As questões para os Licenciandos em Computação foram disponibilizadas digitalmente, através de formulários eletrônicos disponíveis na Internet, com o intuito de aproximar-se dos alunos tão acostumados com a tecnologia no meio acadêmico. $\mathrm{O}$ endereço de acesso ao questionário foi disponibilizado por uma das pesquisadoras e também professora do curso, no $1^{\circ}$ semestre de 2014, através de um e-mail com o convite de participação na pesquisa, salientando-se que foi realizada uma visita prévia das pesquisadoras às classes dos alunos do curso detalhando o motivo da pesquisa.

Vinte e quatro alunos, de diversos períodos da Licenciatura em Computação, se dispuseram a participar da pesquisa e preencheram digitalmente o questionário. Por questões éticas, os sujeitos pesquisados não foram identificados, sendo as respostas analisadas anonimamente.

$\mathrm{O}$ questionário estruturado para os licenciandos era formado por questões objetivas e questões abertas. As perguntas objetivas, com alternativas de resposta "Sim" ou "Não", eram: Quando você optou pelo curso de Licenciatura em Computação realmente desejava ser um professor? Você tem interesse em saber como a escola pública lida com as novas tecnologias? Concorda que a informática deveria ser disciplina obrigatória no currículo das escolas públicas? Para melhor utilização das novas tecnologias na educação seria fundamental a presença dos Licenciados em Computação nas escolas? Você acredita que a presença dos licenciandos em Computação nas escolas públicas pode contribuir para a valorização dos mesmos?

Para análise da participação dos 
licenciandos em Computação em movimento em prol da valorização da carreira docente, os alunos tinham abertura para indicar no questionário de qual movimento participavam na época da realização desta pesquisa. Já em relação aos projetos que valorizam as tecnologias nas escolas públicas, os alunos que indicassem a participação nestes movimentos deveriam citar o nome do projeto, em qual escola e cidade as ações eram desenvolvidas e poderiam descrever a visão da comunidade escolar sobre as tecnologias na educação.

Já o questionário aplicado aos diretores das escolas de educação básica foi impresso e conduzido pessoalmente por uma das pesquisadoras, licencianda em Computação, juntamente com uma carta de apresentação aos membros diretores das escolas que se dispuseram a colaborar com a pesquisa. Foram visitadas apenas as escolas que se manifestaram positivamente quanto à participação na pesquisa, após prévio contato telefônico e/ou por e-mail. Este questionário objetivou obter informações sobre o uso das tecnologias na educação e identificar se as escolas possuem laboratórios de informática, se os alunos e professores os frequentam, se existem nas disciplinas curriculares aulas diferenciadas voltadas para as tecnologias e se as escolas públicas contam com a presença do Licenciado em Computação.

A pesquisa foi realizada em 12 escolas da região sul de Minas Gerais, respectivamente: Campestre (uma escola); Espírito Santo do Dourado (duas escolas); Inconfidentes (uma escola); Machado (duas escolas); Poço Fundo (uma escola); Pouso Alegre (três escolas); São João da Mata (uma escola); e Silvianópolis (uma escola). Destas escolas, 9 são estaduais com níveis de ensino fundamental, médio e técnico e três são municipais, com níveis de ensino infantil e fundamental I $\left(1^{\circ}\right.$ a $5^{\circ}$ ano). $\mathrm{O}$ número de alunos matriculados nessas escolas varia de 122 a 1450 .

As análises interpretativas presentes neste trabalho foram elucidadas a partir do contato com os diretores das escolas pesquisadas bem como através da vivência diária proporcionada pelas atividades do PIBID e de outros projetos de extensão, levando em conta os aspectos sociais e culturais dos envolvidos, bem como a participação na comunidade escolar da Licenciatura em Computação do IFSULDEMINAS, pelo fato de uma pesquisadora ser aluna do $8^{\circ}$ período do curso e a outra pesquisadora ser professora de disciplinas da área técnica neste curso.

\section{Reflexões a partir dos resultados}

Dentre os resultados apresentados neste trabalho estão aqueles referentes ao questionário aplicado aos diretores das escolas da região de Machado quando visitados e perguntados sobre as tecnologias no ambiente educacional. Por questões éticas e de segurança, as escolas não foram identificadas.

Também foram analisadas as respostas dos alunos do curso de Licenciatura em Computação do IFSULDEMINAS aos questionários aplicados, considerando-se a relevância e a valorização desse profissional para os contextos educacional e social. Embora Diniz-Pereira (2014) aponte que até o início dos anos 1980 uma das causas para o número reduzido de pesquisas sobre a formação docente estava no fato de esta ser considerada muito complexa para ser estudada com êxito, esta pesquisa apresenta resultados que podem contribuir para reflexões sobre a formação de professores no campo da computação.

Uma leitura cuidadosa das respostas nos possibilitou a identificação de alguns eixos de análise, os quais apresentamos a seguir.

$\underline{\text { Recursos tecnológicos nas escolas de educação }}$ $\underline{\text { básica }}$

Quando se refere à tecnologia na educação, logo se imagina um espaço físico especial para o desenvolvimento das atividades inovadoras. Segunda Almeida e Júnior (2000, p.70), "uma das ideias mais comuns quando se começa a trabalhar com computadores nas escolas é a de constituir um ambiente específico para isso. O caminho costuma ser a criação de um laboratório de informática". Por essa razão a escola que conta com o laboratório de informática está se abrindo para novo processo de ensino e de aprendizagem tendo o computador como aliado.

Constatou-se que, das 12 escolas pesquisadas, 8 possuem Laboratório de Informática, sendo todos eles com acesso à Internet. $\mathrm{O}$ número de computadores nesses ambientes oscila entre 5 e 20. Observou-se que os computadores foram adquiridos através de licitações nacionais e as máquinas possuem uma configuração técnica que limita o uso de programas com versões mais recentes e instalações de alguns aplicativos que necessitam de maior capacidade de armazenamento e processamento de dados.

Em 5 das 8 escolas que possuem Laboratório de Informática, os alunos e professores utilizam este espaço com certa frequência. Embora não tenham sido áudio-gravados os depoimentos dos diretores enquanto respondiam o questionário, percebemos na fala dos diretores que alguns professores demonstram certo receio e/ou resistência em utilizar as tecnologias digitais em suas aulas. 
Para Almeida e Junior (2000, p.70), "para que a informática possa significar o estímulo capaz de provocar a inovação, e, com ela, a superação de importantes problemas, temos de identificar onde ela pode apresentar possibilidades verdadeiramente novas". Isto nos remete à reflexão sobre o planejamento necessário para a inserção das TDIC na educação, considerando-se, além da disponibilidade dos recursos físicos, a existência de professores motivados para desfrutar destas maneiras de enriquecer o processo pedagógico. A tendência é de se esperar que os professores estabeleçam a conexão entre os recursos tecnológicos e os conteúdos pedagógicos. Mas é necessário que os recursos oferecidos pelas escolas sejam pertinentes às reais necessidades do professor, e torna-se prudente considerar o fato de que o uso das tecnologias é um processo que, assim como outros, demanda certo tempo até que seus benefícios possam ser notados à medida que os professores se sentem familiarizados com os recursos.

Notamos durante a aplicação dos questionários para os diretores das escolas que alguns deles destacam a necessidade de maior atenção governamental para a educação e o trabalho de conscientização dos professores sobre a importância das tecnologias para o processo de ensino e aprendizagem. Para ponderarmos sobre estes fatos, baseamo-nos na seguinte reflexão: "Existe hoje a necessidade de se definir uma visão tecnológica humanista, orientada aos princípios de evolução social, a partir das potencialidades individuais expandidas por meio da tecnologia." (VALENTE; MATTAR, p. 74, 2007).

Para um dos diretores entrevistados, "o oferecimento de cursos nos contraturnos escolares e aos finais de semana poderia ser uma possível condição para que as tecnologias pudessem ser usadas a favor do enriquecimento do processo de ensino e aprendizagem". Não vemos nesta alegação o real motivo e nem a solução para o não uso das tecnologias na educação. Acreditamos que muito além da discussão das condições espaço-temporais está a necessidade de análise das possibilidades de utilização dos recursos tecnológicos nos processos educativos. Tal uso deve ser intrínseco às atividades que comportam a integração dos conteúdos didáticos às tecnologias educacionais desde que planejados adequadamente.

\section{Projetor Multimídia ProInfo e Lousa Digital}

Com o objetivo de levar as TDIC às salas de aula das escolas públicas do país, o Ministério da Educação disponibilizou através do ProInfo, anteriormente denominado Programa Nacional de Informática na Educação, um computador interativo, acoplado a um projetor multimídia, para facilitar o ensino e a aprendizagem. Tanto a lousa digital quanto o computador interativo são artefatos tecnológicos que algumas escolas possuem e que podem ser utilizados pelos professores para o enriquecimento das práticas pedagógicas.

Verificou-se que, das 8 escolas que possuem os referidos recursos tecnológicos, somente em 3 delas os professores utilizam em suas aulas o computador interativo e em 4 escolas utilizam a lousa digital. Constatou-se que em muitas das escolas pesquisadas o computador interativo e a lousa digital, ambos enviados pelo governo, nunca foram utilizados. Acreditamos que isto se deve ao receio dos professores e até mesmo dos diretores em utilizar tais recursos, já que eles foram inseridos fisicamente nas escolas, mas, na maioria das vezes, os educadores e gestores não tiveram a oportunidade de familiarizar-se com estes equipamentos e temem estragá-los ou mesmo passar por situações constrangedoras por não saber manuseá-los. Em uma das escolas parceiras do PIBID Computação foram os alunos de iniciação à docência que apresentaram à comunidade escolar estes recursos educacionais, que estavam guardados na sala da direção sem nunca terem sido utilizados pelos professores.

A escola precisa repensar, conhecer e capacitar os professores para utilizarem as tecnologias como ferramentas a serviço de um projeto pedagógico. Os professores precisam aprender sobre o novo. "A tecnologia será importante, mas principalmente porque irá nos forçar a fazer coisas novas, e não porque irá permitir que façamos melhor as coisas velhas" (DRUCKER apud MACHADO, 2002, p.171).

A escola não é mais a mesma, assim como os alunos não são mais os mesmos. As tecnologias podem contribuir para essa fase de inovação e criatividade da educação. Para Valente (1998), a função dos aparatos educacionais não é a de ensinar, mas sim de criar condições de aprendizagem. Por essa razão, o professor pode ser o criador de ambientes favoráveis e o mediador do processo de ensino e aprendizagem.

Ao perguntar se os professores das escolas pesquisadas receberam alguma capacitação quanto ao uso do projetor interativo e da lousa digital, 7 diretores de escolas responderam que os professores não receberam nenhum treinamento. $\mathrm{O}$ aprendizado de um novo referencial envolve mudança de mentalidade, atitudes reflexivas e transformação. A presença dos licenciados em Computação neste contexto poderia ser fundamental para entender 


\section{reconhecimento profissional}

como as características dos professores interagem com a aprendizagem docente sem ignorar, conforme Zeichner (2009), as práticas dos professores.

Acreditamos que a presença de um profissional licenciado em Computação, com habilidades humanísticas e tecnológicas, pode contribuir para que os professores utilizem as tecnologias no processo de ensino e aprendizagem mas, para isso, eles precisam conhecer e reconhecer, segundo Almeida e Junior (2000), que os computadores, quando utilizados a partir de uma ética e estética humanista, são instrumentos para o belo. Os autores não se referem apenas à beleza e precisão das imagens ou talvez à velocidade da manipulação das informações, mas, à beleza da realização humana e de várias possibilidades expressivas, que podem ser capazes de promover mudanças significativas na educação.

A presença do licenciado em Computação nas escolas de educação básica

Consideramos essencial que os gestores da educação compreendam que, além de Laboratórios de Informática equipados e conectados à Internet, é de grande valia que as escolas tenham um Licenciado em Computação para trabalhar com as tecnologias digitais, objetivando que alunos e professores possam utilizar tais recursos favoravelmente ao processo educacional. Acreditamos nessa premissa ao analisar o perfil dos egressos deste curso e identificar as potencialidades do trabalho interdisciplinar através dos vínculos possíveis entre as teorias computacionais e as disciplinas curriculares.

De forma geral, os licenciados podem desempenhar o papel de mediadores pedagógicos. Mas os licenciados em Computação, por sua formação específica e baseada em premissas peculiares a essa profissão, possuem, em seu currículo, conteúdos característicos para inovação tecnológica das práticas pedagógicas. A partir desta concepção, concordamos com Diniz-Pereira (2014) ao afirmar que a prática dos professores deixa de ser considerada neutra e passa a constituir-se em uma prática educativa transformadora, quando apresenta o histórico da constituição do campo de pesquisa sobre formação docente.

Contrapondo-se à necessidade de valorização dos Licenciados em Computação, que buscamos demonstrar ao longo deste trabalho, das 12 escolas pesquisadas, em relação à presença de recursos humanos para desenvolvimento de práticas pedagógicas nos Laboratórios de Informática, 3 escolas possuem técnicos em Informática, uma escola conta com uma pedagoga e outras duas escolas possuem bacharéis em Sistema de
Informação. Nenhuma das escolas entrevistadas possui no seu quadro de funcionários o perfil profissional do Licenciado em Computação.

As duas escolas pesquisadas na cidade de Machado contam com a presença dos alunos do curso de Licenciatura em Computação do IFSULDEMINAS através de projetos de extensão. Para Zeichner (2009), é preciso investigar como o contexto de formação nos cursos de licenciatura pode influenciar as oportunidades que são dadas aos alunos, futuros professores. Em uma das escolas, um licenciando em Computação é bolsista de extensão, através do instituto, e em outra escola os licenciandos são bolsistas de iniciação à docência do PIBID. Mesmo cientes de que a presença desses alunos na escola é diretamente relacionada à duração destes projetos, os diretores das duas escolas mostraram-se satisfeitos com a atuação e as atividades desenvolvidas por estes alunos.

Os diretores de 9 das 12 escolas pesquisadas demonstraram interesse em ter um professor Licenciado em Computação atuando de forma permanente no planejamento e desenvolvimento das atividades pedagógicas subsidiadas pelas TDIC. Entretanto, estamos diante de uma realidade contrastante: as escolas anseiam ter este profissional, mas não há vagas específicas nas escolas municipais e nem estaduais do estado de Minas Gerais para docentes que se formam em cursos de Licenciatura em Computação.

\section{$\underline{\mathrm{O} \text { desejo em ser professor }}$}

Os cursos de licenciatura preparam os alunos para serem futuros professores. Entretanto, cada disciplina exige um tipo de formação e de formador. Conforme Braga (2007, p.21-22), "a arte de ser professor, de ministrar conteúdos e de educar nos dias de hoje, além de um desfio vocacional, é também uma missão árdua que envolve muita participação e responsabilidade".

Para André (2011), ainda há muito a conhecer a respeito da formação de professores aptos a enfrentar os desafios da educação no século XXI . Muitos licenciandos em Computação vão descobrindo e aprendendo com o decorrer do curso, dedicados à missão de ensinar e aprender, que poderão tornar-se professores responsáveis por mediar as tecnologias a favor da educação e levá-las até a sala de aula.

A primeira pergunta do questionário aplicado aos Licenciandos em Computação fazia referência ao desejo destes alunos em relação a se tornarem professores e não profissionais técnicos de outras áreas da computação. As respostas foram avaliadas por escalas, sendo de 0 a 1 considerado nenhum desejo de seguir a profissão docente e de 2 
a 3 para indicar pouca certeza da escolha da profissão. Já os alunos que optaram pelo intervalo entre 4 e 5 indicavam ter certeza da profissão escolhida. Os resultados revelam que somente oito dos 24 alunos pesquisados, quando escolheram o curso de Licenciatura em Computação, tinham grande desejo de ser realmente professores. Seis alunos não tinham nenhum desejo de ser professor e os outros dez alunos tinham pouca certeza do seu desejo de ser professor.

O cenário emergente após análise destes dados foi apresentado aos professores e alunos do curso de Licenciatura em Computação, durante uma apresentação de Trabalho de Conclusão de Curso, para que eles pudessem refletir sobre as características peculiares desta formação bem como sobre a implementação de estratégias que possam incentivar os egressos a trabalharem como docentes.

Interesse em saber como a escola pública lida com as tecnologias

Conforme Meira (2013), a missão da escola é criar ambientes de aprendizagem capazes de fomentar o interesse dos alunos pelos conteúdos do currículo. Físicos ou virtuais, esses ambientes devem contar com inovações didáticas fundadas na cultura das mídias que estão presentes no cotidiano dos alunos. Considerando-se esta premissa e analisando-se as possibilidades de formação, 88\% dos licenciandos em Computação demonstraram, através dos questionários, interesse em saber como a escola pública lida com as tecnologias.

Por sermos integrantes da comunidade acadêmica da Licenciatura em Computação, esperamos que professores e alunos deste curso dediquem-se à busca constante de alternativas para a aprovação de projetos de ensino, pesquisa e extensão que possam fortalecer o anseio pela valorização do profissional com esta formação e que o curso atenda às expectativas dos seus alunos quanto às possibilidades de atuação no meio educacional, buscando não só utilizar as tecnologias disponíveis mas também desenvolver e incrementar outras possibilidades de valorização das práticas pedagógicas intermediadas pelas tecnologias.

Projetos que visam a valorização dos Licenciandos em Computação

Dos 24 alunos pesquisados, 10 participam de projetos que visam à valorização das TDIC na educação pública, sendo 8 alunos de iniciação à docência do programa PIBID Computação e 2 alunos que participam de projetos de extensão do instituto realizados na cidade de Espírito Santo do Dourado e em Machado (em escola distinta das escolas parceiras do PIBID).
$\mathrm{Na}$ opinião dos licenciandos em Computação que participam dos projetos, eles promovem a sua valorização na comunidade escolar e na sociedade. Consideram que os projetos são oportunidades de os licenciandos mostrarem suas habilidades e competências através das atividades desenvolvidas nas escolas públicas, meio pelo qual convivem com a realidade escolar e despertam para as transformações significativas na educação.

Os licenciandos foram unânimes ao concordar que os projetos despertam maior interesse pelo curso, reforçando o desejo de ser professor. A participação em projetos é responsável por mudanças de pensamentos, valorização e reconhecimento dos Licenciandos em Computação, sendo esses de grande importância para a carreira profissional e contribuindo significativamente para a formação inicial.

Algumas respostas dadas pelos licenciandos como justificativas para a importância da participação em projetos que valorizam as tecnologias na educação merecem destaque. Ressalta-se que, por questões éticas, os questionários foram respondidos de forma anônima e, portanto, as respostas são apresentadas sequencialmente:

O projeto nos leva a estar em contato com a realidade da escola, a convivência dos alunos, $o$ acompanhamento em suas dificuldades. Desperta nos Licenciandos em Computação a vontade de buscar mais conhecimentos de forma a incentivar os professores das escolas a trabalhar os conteúdos, usando recursos propostos pelas TDIC (Licenciando 1, 25/03/2014).

O licenciando 1 alega que a sua participação no PIBID Computação tem permitido sua familiarização com o cotidianos das escolas públicas. Percebe-se ter a oportunidade de acompanhar os alunos no processo de aprendizado o tem levado a buscar formas de incentivo para o uso das TDIC nas práticas educativas.

Com o projeto foi possivel levar um pouco do uso da tecnologia como um recurso educacional para dentro da escola e da sala de aula. Isso nos demonstra que é possível sim aliar o ensino tradicional com o uso da tecnologia motivando tanto os alunos quanto nós futuros professores (Licenciando 2, 26/03/2014).

Destacamos a reflexão feita pelo licenciando 2, após constatar que ele indicou ser 
aluno de iniciação à docência do PIBID Computação, e julgamos prudente considerar que ensinar matemática para os alunos da educação básica não deve ser uma tarefa fácil para ele e nem para os demais bolsistas do projeto. Machado (1987) considera, de forma abrangente, que a dificuldade no ensino desta disciplina apoia-se na imagem dada, por excelência, à matemática, que é tida como o lugar das abstrações, enfatizando-se seus aspectos formais e afastando-a da realidade, tanto para quem aprende como para quem ensina. Entretanto, percebe-se pela sua resposta que o uso das tecnologias tem sido fator de motivação para o desenvolvimento e valorização das práticas pedagógicas subsidiadas pelas TDIC.

Já o licenciando 3 demonstra que os projetos de extensão oferecidos pelo IFSULDEMINAS devem ter lugar de destaque quando são analisadas as possibilidades de enriquecimento das experiências docentes que os alunos vivenciam ao frequentar as escolas públicas:

Acredito que todo projeto que leva o aluno de licenciatura a estar em contato com a realidade e atuar na realidade da escola, principalmente da escola pública, o faz valorizar mais sua licenciatura e o torna interessado em se capacitar cada vez mais, e um dos grandes motivos é que ele percebe a carência de um profissional Licenciado em Computação (Licenciando 3, 26/03/2014).

Com base nessa resposta, sentimo-nos satisfeitas enquanto pesquisadoras e integrantes de projeto de extensão por perceber que as oportunidades dadas aos licenciandos têm permitido que eles valorizem a graduação que estão cursando e passem a vislumbrar a possibilidade de atuação profissional que faça jus à formação que estão vivendo. Tal entusiasmo também está presente na resposta do licenciando 4, que, além do aspecto profissional, destacou o desejo prévio de fazer outro curso que não fosse Licenciatura:

Faço parte do PIBID e acredito que este projeto não só contribui para a valorização dos Licenciados em Computação como também contribui para que o próprio Licenciado se identifique como tal. No meu caso, por exemplo, ao ingressar no curso, o meu foco era totalmente diferente do que é hoje (Licenciando 4, 26/03/2014).

Gadotti (2004) descreve o professor como um mediador do conhecimento, um aprendiz permanente frente ao aluno, que tem papel de sujeito de sua própria formação. Alguns fatores se destacam: o gosto de aprender; o prazer em ensinar e o amor ao discente. Percebemos pelas respostas dos licenciandos 5 e 6 que a possibilidade de participação em projetos de extensão fizeram com que eles pudessem descobrir novas oportunidades para o aprimoramento das práticas pedagógicas e a valorização da carreira docente:

A participação no PIBID despertou minha visão para a necessidade de inclusão das TDIC no espaço-escola em paralelo com a globalização. $E$ hoje, quero muito desenvolver trabalhos e projetos que contribuam para melhorar o ensino através das tecnologias (Licenciando 5, 26/03/2014).

Ter a oportunidade de desenvolver na prática os conteúdos vistos em sala de aula despertou não só o interesse pela Licenciatura em Computação, mas também, para uma carreira como professora (Licencianda 6, 26/03/2014).

Após a análise de cunho qualitativo das respostas dadas pelos licenciandos em Computação às perguntas abertas do questionário estruturado que lhes foi aplicado, apontamos que os projetos, sejam eles promovidos como extensão pelo IFSULDEMINAS ou desenvolvidos por meio de políticas públicas de iniciação à docência, evidenciam as transformações significativas na carreira dos futuros professores. Acreditamos que, apesar da importância destes projetos, eles contemplam números ainda reduzidos de vagas em relação ao quantitativo de alunos matriculados.

\section{Considerações finais}

Para que as escolas possam envolver alunos e professores na era digital, o governo tem lançado alguns programas e investido em equipamentos eletrônicos como lousas digitais, projetores interativos e laboratórios de informáticas. Todavia, um dos grandes desafios é cativar o professor para que ele utilize os meios tecnológicos como ferramenta pedagógica para que os alunos possam estudar em uma escola compatível com seu tempo.

A pesquisa realizada reforçou a necessidade de um profissional qualificado, com competências e habilidades pedagógicas e tecnológicas para favorecer a relação entre professores e recursos digitais nas escolas públicas do sul de Minas Gerais: o licenciado em Computação. Entretanto, o cenário que se forma remete-se a um paradoxo de formação: 
os diretores das escolas de educação básica almejam a presença desse profissional, os professores já atuantes não se sentem seguros para trabalhar com a tecnologia, os licenciandos estão se aproximando da profissão como consequência direta de projetos de iniciação à docência e estão aprendendo a gostar da profissão docente, mas, infelizmente, ainda não existem vagas para os licenciados em Computação nas escolas públicas de Minas Gerais.

Após entrevistar os diretores das escolas públicas por meio de questionários estruturados, algumas questões ficaram evidentes como a resistências ao "novo" por parte dos professores, a necessidade da sua formação contínua e a carência de um profissional capacitado pedagogicamente e em computação para coordenar as atividades acadêmicas vinculadas às TDIC. A pesquisa mostrou que esse profissional ainda não é encontrado nas escolas públicas, embora estas sejam os locais de visível contexto de aprendizagem.

A participação em projetos de extensão foi considerada pelos licenciandos uma forma de valorização do curso de Licenciatura em Computação, e através das ações propostas a comunidade escolar e a sociedade são beneficiadas ao mesmo tempo em que reconhecem as habilidades e competências deste profissional.

As tecnologias não trazem as soluções para programas de baixa qualidade educacional, não consertam os erros e os problemas da educação. A tecnologia não é um efeito mágico, mas através dela pode-se sugerir e construir um plano pedagógico adequado, focado, motivador, crítico e inovador porque o sucesso de sua inserção no ambiente educacional depende de quem a usa, a favor de que, de quem e para quê.

A inserção da disciplina de Informática na educação básica deve ser vista como um projeto multidisciplinar para que sejam utilizadas ferramentas e programas computacionais que enriqueçam as práticas pedagógicas, tornando o professor o mediador e o aluno o autor do seu próprio conhecimento, promovendo o pensamento lógico e aprendizagem contínua.

A necessidade da disciplina de informática educativa é defendida por Almeida e Junior (2000), ao afirmarem que a informática trará novas possibilidades ao processo educacional, resultando em uma aprendizagem mais eficiente, mais abrangente, mais confortável, mais motivadora e inovadora, sendo este o caminho para a construção de uma sociedade mais humana e digna.

A inclusão de computadores no processo pedagógico pode permitir que os alunos produzam seu próprio conhecimento e consequentemente contribuam para uma educação de qualidade.
Todavia, este contexto só fará sentido se forem planejadas as ações que possam vir a contribuir efetivamente para que as TDIC não sejam apenas recursos, mas que criem estratégias de valorização do processo de ensino e aprendizagem.

Entendemos haver necessidade de investimento em equipamentos e manutenção bem como na capacitação dos professores para o uso efetivo das TDIC. Porém identificamos também a necessidade do licenciado em Computação nas escolas para que a comunidade reconheça que esse profissional possui pleno desejo de enriquecer as práticas pedagógicas multidisciplinares.

Espera-se que esta pesquisa possa contribuir para se repensar sobre a continuidade do curso de Licenciatura em Computação do IFSULDEMINAS bem como ampliar o debate sobre a inserção das tecnologias em sala de aula, com laboratórios que não funcionam e professores pouco motivados para o seu uso. Nesse sentido, o trabalho colaborativo entre o profissional da computação, com formação para ser professor, e o professor de outras áreas seria extremamente benéfico para a aprendizagem dos alunos a partir do momento em que as práticas pedagógica se tornarem mais interativas $\mathrm{e}$ contextualizadas.

\section{Notas}

1 A resolução de autorização do curso de Licenciatura em Computação do IFSULDEMINAS foi publicada no Diário Oficial da União $\mathrm{n}^{\circ} 227$ de 27 de novembro de 2009, referendado pela resolução do Conselho Superior $n^{\circ}$. 009/2010, de 26 de janeiro de 2010

2 Acessível na Internet pelo endereço $<$ https://www.facebook.com/groups/LicComputac ao QueremosContato/?fref =ts $>$

\section{Referências}

ALMEIDA, F. J. e JÚNIOR, F. M. F. ProInfo: Projetos e Ambientes Inovadores.v.1. Brasília: Ministério da Educação, SEED,2000.

ALMEIDA, M. E. ProInfo: Informática e Formação de Professores.v.1.Brasília: Ministério da Educação, SEED,2000.

ALONSO, A. S. M. O método e as decisões sobre os meios didáticos. In: SANCHO, J.M. (Org.). Para uma tecnologia educacional. Porto Alegre: Artes Médicas, 1998. 
ANDRÉ, M. Pesquisas sobre formação de professores, tensões e perspectivas do campo. In: FONTOURA, H. A; SILVA, M (Orgs.). Formação de professores, culturas desafios à Pós-graduação em Educação e suas múltiplas dimensões. E-book online. X Encontro de Pesquisa em Educação da Região Sudeste. ANPED Sudeste, 2011. Disponível em http://www.fe.ufrj.br/anpedinha2011/sobre.html, p.24-36.

BORBA, M.C. GPIMEM e UNESP: Pesquisa, Extensão e Ensino em Informática e Educação Matemática. In: Miriam Godoy Penteado; Marcelo de Carvalho Borba. (Org.). A informática em ação: formação de professores, pesquisa e extensão. 1ed. Rio Claro: Olhos d'Água, 2000, v. 1, p. 47-66.

BORBA, M.C. O computador é a solução: mas qual é o problema? In: SEVERINO, A.J., FAZENDA, I.C.A. (orgs). Formação docente: Rupturas e possibilidades. Campinas, SP: Papirus, 2002.

BITTENCOURT, I.M. ; BITTENCOURT, I. G. S. Como professores concebem o uso das TIC em suas práticas pedagógicas. In: V Encontro de Pesquisa em Educação em Alagoas - EPEAL, 2010, Maceió. Pesquisa em Educação: Desenvolvimento, Ética e Responsabilidade Social. Maceió: EDUFAL, 2010.

BRAGA, J. G. Educar seria ruim se fosse fácil. $1^{\text {a }}$ ed. Uberaba: CNEC Edigraf, 2007.

BRASIL. Portaria Normativa $\mathrm{n}^{\circ} 38$, de 12 de dezembro de 2007. Dispõe sobre o Programa Institucional de Bolsa de Iniciação à Docência PIBID. Diário Oficial da União, n. 239, seção 1, p. 39, 2007.

BRASIL. Presidência da República. Casa Civil. Lei $\mathrm{n}^{\circ} 11.892$, de 29 de dezembro de 2008. Disponível em

<http://www.planalto.gov.br/ccivil_03/_ato2007-

2010/2008/lei/111892.htm>. Acesso em 21 de outubro de 2014.

DALABONA, J. S. Uma reflexão sobre o uso de materiais digitais em atividades de Matemática. Monografia de Especialização em Informática na Educação. Porto Alegre: CINTED-UFRGS, 2005.

DELORY-MOMBERGER, C. Biografia e educação: figuras do indivíduo-projeto. Natal: UFRN. São Paulo: Paulus, 2008.

DEMO, P. Pensando e fazendo educação: inovações e experiências educacionais. Brasília:
Liber Livro, 2011.

DINIZ-PEREIRA, J. E. O campo de pesquisa sobre formação de professores. In: SOUZA, J. V. A. de; DINIZ, M; OLIVEIRA, M. G. (Orgs.). Formação de professores (as) e condição docente. Belo Horizonte, MG: Ed. UFMG, 2014, p. 101-119.

DOMINICÉ, P. O processo de formação e alguns dos seus componentes relacionais. In: NÓVOA, A; FINGER, M. (orgs.). O método (auto)biográfico e a formação. Natal: UFRN; São Paulo: Paulus, 2010, p.81-95.

FREIRE, P. A educação na cidade. 2. São Paulo: Ed. São Paulo, 1995.

Gadotti, M. Informação, conhecimento e sociedade em rede. Que potencialidades? In: Fórum Paulo Freire - IV Encontro Internacional Caminhando para uma cidadania multicultural. Universidade do Porto. 2004.

IFSULDEMINAS - CÂMPUS MACHADO. Projeto Político Pedagógico do curso de Licenciatura em Computação. Machado, 2012. Disponível em

http://www.mch.ifsuldeminas.edu.br/images/stories/ cursos-tabelas/Licenciatura-em-

Computacao/Licenciatura\%20em\%20Computacao.p df>. Acesso em 10 de novembro de 2013.

KENSKI, V. M. Novas tecnologias, o redimensionamento do espaço e do tempo e os impactos no trabalho docente. Trabalho apresentado na XX Reunião Anual da ANPED, Caxambu, setembro de 1997. Disponível em $<$ http://anped.org.br/rbe/rbedigital/RBDE08/RBDE 08_07_VANI_MOREIRA_KENSKI .pdf>. Acesso em 6 de novembro de 2013.

MACHADO, N. J. Matemática e Realidade. São Paulo: Cortez, 1987.

MACHADO, N. J. Epistemologia e Didática: as concepções de conhecimento e inteligência e a prática docente. São Paulo: Cortez, 2002.

MEIRA, L. Cultura digital e ensino. Revista Pátio Ensino Médio Profissional e Tecnológico. Porto Alegre/Referências de sites da Internet: Grupo Educação S.A, v. 19, 12/2013/ 02/2014, p.07-09. Trimestral. 2013.

MENDES, R. M. A formação docente do professor de Matemática, os jogos 
computacionais e as comunidades de prática: uma relação possível. 2013. Tese (Doutorado em Educação Matemática). Rio Claro: UNESP.

PERRENOUD, P. Dez novas competências para ensinar. (Tradução de Patrícia Chittoni Ramos). Porto

Alegre: Artes Médicas Sul, 2000.

VALENTE, J. A. Diferentes usos do computador na educação. In: Valente, J. A. (Org). Computadores $\boldsymbol{e}$ Conhecimento: repensando a educação. Campinas:
Gráfica Central da Unicamp, 1998.

VALENTE, C; MATTAR, J. Second Life e Web 2.0 na Educação - o potencial revolucionário das novas tecnologias. São Paulo: Novatec, 2007.

ZEICHNER, K. M. Uma agenda de pesquisa para a formação docente. Revista Brasileira de Pesquisa sobre Formação Docente. Belo Horizonte, v.1, n.1, p.13-40, ago./dez.2009. Disponível em: http://formacaodocente.autenticaeditora.com.br.

Acesso em 06 de outubro de 2014.

\section{Sobre as autoras:}

Cristina Carvalho de Almeida: Doutoranda da Universidade São Francisco - Itatiba / SP. Professora do Instituto Federal de Educação, Ciência e Tecnologia do Sul de Minas Gerais (IFSULDEMINAS) Câmpus Machado.

Noemi Marcia Alvarenga Mateus: Licenciada em Computação pelo IFSULDEMINAS - Câmpus Machado. Professora em Espírito Santo do Dourado / MG.

Artigo recebido em janeiro de 2015.

Artigo aprovado em maio de 2015. 